\title{
Energy Drinks Consumption Patterns Among Young Kuwaiti Adults
}

\author{
Tahani Al-Waalan* and Reem Al Khamees \\ Food and Nutrition Program, Kuwait Institute for Scientific Research, Kuwait
}

\begin{abstract}
Energy drinks are a group of beverages that have become increasingly popular with the Kuwaiti youth consumers to provide extra energy, promote wakefulness, maintain alertness, and provide cognitive and mood enhancement. The purpose of this study is to assist in establishing whether energy drinks constitute a health risk on young Kuwaiti population. A questionnaire was distributed to assess the situation in which they use energy drinks, the most common energy drinks they used, frequency pattern per month and the side effects. Based on the response of (570) participants, a random selection group from teenagers and adult participants were given a can of their favorite energy drink to measure the parameters of this study: blood sugar level, blood pressure and heartbeats. The results showed that prevalence of energy drink consumption is $58.3 \%$ of those who consume one or more energy drink per month. Most common reason for this high prevalence is enjoying energy drink's taste and increasing energy in general. With regards to the adverse effects, numerous volunteers reported several symptoms including increased heart rate, restlessness, heart palpitations, high blood pressure and a high chance of addiction. Additionally, energy drinks with high sugar content are a serious threat to the consumer's health, as it may lead to obesity and severe health complications.
\end{abstract}

\section{Background}

Energy drinks were introduced to the market in 1997, with the current leader in the energy drink market, Red Bull. Energy drinks productions have become a rapidly growing industry, launching 500 and more energy drinks around the world [1]. Advertisements introduced the energy drink in the Arabic countries as a drink that gives you wings; it gained popularity rapidly among the youth. These drinks became popular among the younger generation, especially in the Arabian Gulf countries were young individuals account for the majority of their societies. For this reason, in the last five years, $70 \%$ of energy drink consumers were between the ages of 19 to 29 [2].

Energy drinks are caffeinated beverages that generally contain large doses of sugar, carbohydrates, and a variety of legal stimulants and supplements [3]. Vitamins and other herbal supplements are added for the purpose of enhancing the stimulants like caffeine,

\footnotetext{
* Corresponding author: tahanialwaalan@gmail.com
} 
taurine, l-carnitine and glucuronolactone [4]. Caffeine is commonly used as a psychoactive substance in the world and imposes a potentially destructive influence on health, academic performance, and personal adjustments [5]. Energy drinks have a caffeine concentration ranging from none detected to $141.1 \mathrm{mg} / \mathrm{serving}$. On the other hand, the caffeinated soda's caffeine concentrations range from none detected to $48.2 \mathrm{mg} / \mathrm{serving}$ and the content of the other beverages ranged from $<2.7$ to $105.7 \mathrm{mg} /$ serving [6].

The excessive consumption, rapid growth and the popularity of energy drinks among adolescents and young adults have established a concern of overall health and well-being [5]. These drinks have appeared in the market as alternatives that promote fun and improvement of physical and cognitive performance such as concentration, attention, and alertness [3]. Young adults and teenagers are the primary consumers of energy drinks as they form approximately $\$ 2.3$ billion of energy drink sales. However, they are usually oblivious to the fact that energy drinks contain caffeine, and that the accumulation of caffeinated products can cause caffeine toxicity and severe adverse effects [5, 7]. Research has revealed that energy drinks consumers find risk-taking behavior more appealing than non-energy drink consumers. Several of the reported physiological symptoms include; heart palpitations, sleep difficulties, agitation, tremors, and jolt and crash episodes; whereas, psychological symptoms include irritability and tension [8]. Moreover, increased consumption of energy drink leads to addiction, which may lead to dehydration, seizures, acute mania and strokes [9]. Further side effect of energy drink consumption is the increased risk of obesity due to their high sugar content [10].

According to a report by researchers at the University of Miami Miller School of Medicine published in the Journal Pediatrics [11], energy drink consumption may be hazardous for some children and young adults especially those with diabetes, seizures, heart abnormalities or mood and behavior disorders. Yet, the beverage industry strongly disputes with this. Some companies have indirectly been unreliable to customers about their products by putting warnings on the outer shell that these drinks are not suitable for diabetics, blood pressure patients, heart and arteries patients, pregnant women, and children under the age of eighteen years old [12]. Recent advances in the field of prediction medicine developed expert systems that can predict and diagnose diabetes and such system can be very useful to help control the disease [13].

Energy drinks have been proven to cause detrimental health problems and may possibility lead to death [14] In the recent years, Kuwait has reported few death cases of young adults who consumed relatively high amounts of energy drinks (few cans) before they collapsed and were taken to hospital. Based on existing research, no previous surveys have been conducted in Kuwait to investigate the consumption pattern of energy drinks among Kuwaiti youth. The purpose of this study is to (1) assist in establishing whether energy drinks constitute a health risk and (2) assessing the potential exposure of young Kuwaiti population to possible hazards and side effects in energy drinks which are popular in local markets.

\section{Methods}

A questionnaire was designed to assess the consumption pattern of energy drinks among the young Kuwaiti generation. At first, a focused group of 25 participants were interviewed with open-ended questions regarding the situation in which they consume energy drinks, the most common energy drinks consumed, frequency pattern per month and side effects from energy drinks consumption. The trail study was written according to the Kuwaiti lifestyle, based on their sleeping hours and caffeine consumption. The participants were of different age groups and different areas in Kuwait to ensure the accuracy and validity of the questionnaire. 
Based on the response of the pilot study participants, a questionnaire was developed. Questions 1, 2 and 3 will assess demographic information (gender, age and education level). Question 4 will be used to identify energy drink users and ask, "Do you drink more than one energy drink in a month?", If participants indicate "no", they will be instructed to skip the remaining questions in the survey and return the questionnaire to the research assistant. Participants who will indicate "yes" to Question 4 will be instructed to continue the survey, which will assess the type of energy drink usually consumed (regular or sugar-free) and the side effects associated with energy drink use.

Twenty volunteers, from ages 18 to 26 , were chosen randomly to measure physiological change regarding energy drink consumption through visitations to public colleges and universities. The physiological measurements were based on three variable factors, blood glucose, blood pressure and heart rate, beginning with a baseline and 30 min intervals for an hour and a half. Blood glucose was measured using a glucose meter (OptiumXceedAbbott CE0088, China) and blood pressure and heart rate were measured using a heart monitor (ALPK2, DS-157, Japan). A baseline was taken, followed by the consumption of a predefined amount $(150 \mathrm{ml})$ of energy drink (Red Bull) and the measurements were initiated.

The Medcalc software (MEDCALC, Belgium) was used to conduct the statistical analysis. The statistics included means, standard deviations, 95\% confidence intervals, and frequency distributions. Pearson X2 was used to evaluate the difference in frequency distribution of responses. An alpha level of 0.05 was used for all statistical tests.

\section{Results}

A total of 570 participants, 245 males with an average age of $20.1 \pm 6.5$ y (95\% Cl, 19.2, 20.9), and 325 females with an average age of $16.4 \pm 4.4$ y (95\% Cl, 16.0, 16.9) completed the energy drink questionnaire in this study. In regard to the energy drink consumption, the statistical data illustrated that a higher consumption rate was within the male group with a percentage of 61.2 when compared to a percentage of 56.0 of female consumers. To simplify, the data showed a total number of energy drink consumers of 332 (58.3\%) and $238(41.8 \%)$ did not consume energy drinks. Based on the participants' age, elementary students (9 to $10 \mathrm{y}$ old) had $9.1 \%$ participation. In this category, male drinkers were $43.9 \%$ and female drinkers were 54.5\%. Intermediate level (11 to $14 \mathrm{y}$ old) had $28.9 \%$ of participation, $61.5 \%$ of males were drinkers and $57.6 \%$ of females. High school students (15 to 18 y old) participation was $23.0 \%$, where $78.3 \%$ were the male drinkers and $77.6 \%$ were the females. The 19+ years old participants, educational level ranging from diploma, bachelor, and post-graduate, had a participation percent of 5.1, 28.8 and 4.2 respectively. Male drinkers in this age group were $52.2 \%, 65.2 \%$ and $50.0 \%$, respectively, whereas female percentages were 33.3, 29.3 and 75.0. Employed participants who were from the $19+$ age group, had a participation of $18.9 \%$, where the male drinkers were $62.3 \%$ and the females were $26.1 \%$ (Shown in Table 1 ).

In regard to the sugar content of the energy drinks, more than half of the energy drink consumers drink regular type of energy drink (56\% male, $66 \%$ female). Sugar-free energy drinks are not popular, with only $26.7 \%$ male drinkers and $6.0 \%$ female. Energy drink users unaware of the sugar content were $16.7 \%$ males and $48.7 \%$ females. Most energy drinks consumers, $54.2 \%$ males and $50.0 \%$ females, preferred to drink the energy drink alone. A minority, only $10.6 \%$ males and $9.4 \%$ females, preferred it mixed with other drinks.

Regarding the question addressing the side effects of energy drink consumption, rapid heartbeat was reported as the most common side effect, $40.0 \%$ male and $60.0 \%$ female. Headaches were considered the second side effect, with $41.9 \%$ male and $58.1 \%$ females. 
Moreover, loss of sleep and sweating had similar percentages with males at (51.9\%, 51.1\%), and females at $(48.1 \%, 48.9 \%)$, respectively. Many females (84.4\%) reported not feeling anything during and after consumption, however, only $15.6 \%$ of males reported likewise. The side effects did not differ significantly by gender, with loss of sleep, $\mathrm{X} 2(1, \mathrm{~N}=52)=$ 0.019, $\mathrm{p}=0.8897$, rapid heartbeat, $\mathrm{X} 2(1, \mathrm{~N}=60)=2.017, \mathrm{p}=0.1556$, headache, $\mathrm{X} 2(1, \mathrm{~N}$ $=62)=1.306, \mathrm{p}=0.2530$, and sweating, $\mathrm{X} 2(1, \mathrm{~N}=47)=0, \mathrm{p}=1.00$. (Shown in Table 2$)$

Table 1. Distribution of participation, education level and consumption of responder's $M=$ males, $F$ $=$ females, $\mathrm{D}=$ Drinkers, ND = Non-drinkers.

\begin{tabular}{|c|c|c|c|c|c|c|c|c|}
\hline & $\begin{array}{c}\text { Educatio } \\
\mathbf{n}\end{array}$ & $\begin{array}{c}\text { Elementar } \\
\mathbf{y}\end{array}$ & $\begin{array}{c}\text { Intermedia } \\
\text { te }\end{array}$ & $\begin{array}{c}\text { High } \\
\text { Schoo } \\
\text { l }\end{array}$ & $\begin{array}{c}\text { Diplom } \\
\text { a }\end{array}$ & $\begin{array}{c}\text { Bachelo } \\
\text { r }\end{array}$ & $\begin{array}{c}\text { Post- } \\
\text { Graduat } \\
\text { e }\end{array}$ & $\begin{array}{c}\text { Employe } \\
\text { d }\end{array}$ \\
\hline & Yrs. & $(9-10)$ & $(11-14)$ & $\begin{array}{l}(15- \\
18)\end{array}$ & $(19+)$ & $(19+)$ & $(22+)$ & \\
\hline \multirow{2}{*}{ M } & D (\%) & 18 (43.9) & $16(61.5)$ & $\begin{array}{c}36 \\
(78.3)\end{array}$ & $\begin{array}{c}12 \\
(52.2)\end{array}$ & $\begin{array}{c}58 \\
(65.2)\end{array}$ & $10(50.0)$ & 53 (62.3) \\
\hline & ND (\%) & $23(56.1)$ & 10 (38.5) & $\begin{array}{c}10 \\
(21.7)\end{array}$ & $\begin{array}{c}11 \\
(47.8)\end{array}$ & $\begin{array}{c}31 \\
(35.2)\end{array}$ & $10(50.0)$ & 32 (37.6) \\
\hline \multirow{3}{*}{$F$} & D (\%) & $6(54.5)$ & 83 (57.6) & $\begin{array}{c}66 \\
(77.6)\end{array}$ & 2 (33.3) & $\begin{array}{c}22 \\
(29.3)\end{array}$ & $3(75.0)$ & 06 (26.1) \\
\hline & ND (\%) & 5 (45.5) & 61 (42.4) & $\begin{array}{c}19 \\
(34.5)\end{array}$ & $4(66.7)$ & $\begin{array}{c}53 \\
(70.7)\end{array}$ & $1(25.0)$ & 17 (73.9) \\
\hline & All (\%) & $52(9.1)$ & 170 (29.8) & $\begin{array}{l}131 \\
(23)\end{array}$ & $29(5.1)$ & $\begin{array}{c}163 \\
(28.8)\end{array}$ & $24(4.2)$ & $\begin{array}{c}108 \\
(18.9)\end{array}$ \\
\hline
\end{tabular}

Table 2. Side effects from energy drink consumption according to gender

\begin{tabular}{cccccc}
\hline Side-effect & N (\%) & Male (\%) & Females (\%) & X2 & P (sex) \\
\hline $\begin{array}{c}\text { Loss } \\
\text { of sleep }\end{array}$ & $52(20.1)$ & $27(51.9 \%)$ & $25(48.1 \%)$ & 0.019 & 0.8897 \\
Rapid heartbeat & $60(23.7)$ & $24(40.0 \%)$ & $36(60.0 \%)$ & 2.017 & 0.1556 \\
Headache & $62(24.5)$ & $26(41.9 \%)$ & $36(58.1 \%)$ & 1.306 & 0.2530 \\
Sweating & $47(18.6)$ & $24(51.1 \%)$ & $23(48.9 \%)$ & 0.000 & 1.0000 \\
None & $32(12.6)$ & $5(15.6 \%)$ & $27(84.4 \%)$ & 13.781 & 0.0002 \\
\hline
\end{tabular}

an $=253$ Kuwaiti energy drink users

While comparing the side effects with regard to the daily, weekly and monthly intake of energy drinks, it was found that many of these side effects were linked to a specific consumption pattern. We found that a few participants consumed more than one can per day, and the most common side effect of this category was rapid heartbeat with a percent of 50.0. On the other hand, $33.3 \%$ participants in the category of daily consumption had headache as the most common side effect, followed by loss of sleep and rapid heartbeat, both with an equal percent of 23.0. For a consumption pattern of 3-4 times per week, headache was the common side effect with percent of 38.1, sweating was second with a high percent of 28.6. For the once per week consumption category, loss of sleep had the highest percent with 31.0, and rapid heartbeat was the second most common with $23.6 \%$. Moreover, consumers of one can per month had rapid heartbeat as the most common side effect with a percent of 32.1. (Shown in Table 3)

While addressing the reason for energy drink consumption, the first reason for both genders was the taste of the energy drink with a percent of 49.13 for female and 38.9 for male. The reason of consumption for energy was second for both genders with $32.95 \%$ for females and $26.39 \%$ for males. The consumption for the need to stay awake came in third 
for both males and females with $19.44 \%$ and $10.98 \%$, respectively. The consumption for studying or working was only $4.86 \%$ for males and 3.45\% for females (Shown in Table 4).

Table 3. Side effects based on the consumption rate of the participants

\begin{tabular}{cccccc}
\hline Side-effect & One/ Month & One/ Week & 3-4/ Week & Daily & $\begin{array}{c}\text { More than 1 } \\
\text { Daily }\end{array}$ \\
\hline Loss of sleep & $11(20.7)$ & $17(31.0)$ & $09(10.7)$ & $11(23.0)$ & $4(33.3)$ \\
Rapid heartbeat & $17(32.1)$ & $13(23.6)$ & $13(15.5)$ & $11(23.0)$ & $6(50.0)$ \\
Headache & $09(17.0)$ & $05(09.1)$ & $32(38.1)$ & $16(33.3)$ & $0(0.0)$ \\
Sweating & $04(07.5)$ & $10(18.2)$ & $24(28.6)$ & $08(16.7)$ & $1(12.5)$ \\
None & $12(22.6)$ & $10(18.2)$ & $06(07.1)$ & $02(04.2)$ & $1(12.5)$ \\
Total & 53 & 55 & 84 & 48 & 12 \\
\hline
\end{tabular}

Table 4. Reasons of energy drink consumption according to gender.

\begin{tabular}{ccc}
\hline Reasons for energy drink consumption & Male (\%) & Female (\%) \\
\hline For sports & $08(05.55)$ & $03(01.73)$ \\
Friends encouragement & $01(00.69)$ & $02(01.16)$ \\
Like their taste & $56(38.89)$ & $85(49.13)$ \\
Long time driving & $04(02.78)$ & $00(00.00)$ \\
Need energy & $38(26.39)$ & $57(32.95)$ \\
Stay awake & $28(19.44)$ & $19(10.98)$ \\
Stimulate my metabolism & $02(01.39)$ & $00(00.00)$ \\
While studying/ working & $07(04.86)$ & $06(03.45)$ \\
\hline
\end{tabular}

For the question which concerns the reasons for not consuming energy drinks, most participants, 35.4\% for both males and females, were concerned about the side effects. With not having the need to drink it, $27.8 \%$ came as the second most common answer, and not liking the taste had $22.2 \%$. The reason for not drinking was because of parents not allowing it was the least with only $14.6 \%$. (Shown in Table 5)

Table 5. Reason for not consuming energy drinks according to gender.

\begin{tabular}{cccc}
\hline Reasons & N (\%) & Male & Female \\
\hline Don't feel like I need it & $080(27.8)$ & 29 & 51 \\
Don't like the taste & $064(22.2)$ & 20 & 44 \\
Heard about the side & $102(35.4)$ & 50 & 52 \\
effect & $042(14.6)$ & 15 & 27 \\
Parents don't allow & &
\end{tabular}

an $=288$ of Kuwaiti non-drinkers.

The physiological measurements after energy drink consumption $(150 \mathrm{ml})$ were taken for 22 young adult volunteers between the ages of 17 to $26 \mathrm{y}$. The results showed that blood glucose increases after $30 \mathrm{~min}$ of consumption, reaching its peak, and then declines gradually to the normal baseline. On the other hand, heart rate dropped after $30 \mathrm{~min}$ of consumption and then increased dramatically until $60 \mathrm{~min}$, where it continued to increase but slowly. For the blood pressure, as shown in (Table 6), it appeared not to be affected by energy drinks; it remained stable from baseline measurement to $90 \mathrm{~min}$. 
Table 6. Average blood pressure, heart rate and blood glucose before and after consumption of energy drinks.

\begin{tabular}{ccccc}
\hline Time & $\begin{array}{c}\text { Blood Pressure } \\
\text { Systolic }\end{array}$ & $\begin{array}{c}\text { Blood Pressure } \\
\text { Diastolic }\end{array}$ & Heart Rate & Blood Glucose \\
\hline minutes & $\mathrm{mmHg}$ & $\mathrm{mmHg}$ & beats/minute & $\mathrm{mmol} / \mathrm{L}$ \\
Baseline & $120 \pm 19.2$ & $75 \pm 17.2$ & $85.0 \pm 15.5$ & $6.0 \pm 1.6$ \\
30 & $117 \pm 20.5$ & $75 \pm 18.2$ & $84.3 \pm 17.8$ & $7.3 \pm 1.4$ \\
60 & $117 \pm 25.5$ & $77 \pm 20.3$ & $92.0 \pm 20.0$ & $6.3 \pm 1.1$ \\
90 & $118 \pm 22.0$ & $80 \pm 29.0$ & $93.0 \pm 23.0$ & $5.6 \pm 1.1$ \\
\hline
\end{tabular}

T-test 1:

$\mathrm{H} 0=$ There is no difference in the participants' blood glucose levels and if the participants been diagnosed with fast heart rate or not. (H0: $\boldsymbol{\mu} 1=\boldsymbol{\mu} 2)$

Independent sample t-test 95\%CI [-0.59 - 2.16] was statistically significant when comparing the mean (SD) blood glucose levels of participants at Min60 with the participants being diagnosed with fast heart rate or not $p$-value $=0.235$. The mean (SD) blood glucose levels at Min60 for participants diagnosed with fast heart rate was 7.73 (1.69) statistically significant different from the mean (SD) blood glucose levels at Min60 of participants that never were diagnosed with fast heart rate 6.95 (1.03). The difference in the mean blood glucose levels at Min60 was 0.78 higher for participants diagnosed with fast heart rate. On average blood glucose levels of participants diagnosed with fast heart rate are 0.78 higher than participants diagnosed with normal heart rate. The difference could be between -0.59 to 2.16. (Shown in table 7)

Table 7. Association between participant Blood Glucose levels and whether diagnosed with Fast Heart Rate or not. $(\mathrm{n}=22)$

\begin{tabular}{|ccccccc}
\hline & $\begin{array}{c}\text { Diagnosed with } \\
\text { Fast Heart } \\
\text { Rate } \\
\mathbf{n = 9}\end{array}$ & $\begin{array}{c}\text { Diagnosed with } \\
\text { Normal Heart } \\
\text { Rate } \\
\mathbf{n = 1 3}\end{array}$ & $\begin{array}{c}\text { Ddifference } \\
\text { in means }\end{array}$ & $\mathbf{9 5 \% ~ C I ~}$ & p- value \\
\hline $\begin{array}{c}\text { Mean (SD) Blood } \\
\text { Glucose levels at } \\
\text { Min60 }\end{array}$ & $7.73(1.69)$ & $6.95(1.03)$ & 0.78 & $\begin{array}{c}\text { [-0.59, } \\
2.16]\end{array}$ & 0.235 \\
\hline
\end{tabular}

95\%CI and p-value reported from Independent sample t-test

\section{T-test 2:}

$\mathrm{H} 0=$ There is no difference in the participants' systolic blood pressure levels and if the participants been diagnosed with fast heart rate or not. (H0: $\boldsymbol{\mu} 1=\boldsymbol{\mu} 2)$

Independent sample t-test 95\%CI [-14.30 - 23.66] was statistically significant when comparing the mean (SD) systolic blood pressure levels of participants at baseline with the participants being diagnosed with fast heart rate or not $p$-value $=0.606$. The mean (SD) systolic blood pressure at baseline for participants diagnosed with fast heart rate was 122.44 (22.3) statistically significant different from the mean (SD) systolic blood pressure at baseline of participants that were diagnosed with normal heart rate 117.77 (17.44). The difference in the mean systolic blood pressure levels at baseline was 4.23 higher for participants diagnosed with fast heart rate. On average systolic blood pressure levels of participants diagnosed with fast heart rate are 4.23 higher than participants with normal diagnosed heart rate. The difference could be between -14.40 to 0.606. (Shown in table 8) 
Table 8. Association between participant Systolic Blood Pressure levels and whether diagnosed with Fast Heart Rate or not. $(\mathrm{n}=22)$

\begin{tabular}{|c|c|c|c|c|c|}
\hline & $\begin{array}{c}\text { Diagnosed with } \\
\text { Fast Heart Rate } \\
\text { n=10 }\end{array}$ & $\begin{array}{c}\text { Diagnosed with } \\
\text { Normal Heart } \\
\text { Rate } \\
\text { n=12 }\end{array}$ & $\begin{array}{l}\text { Ddifference } \\
\text { in means }\end{array}$ & $95 \%$ CI & p- value \\
\hline $\begin{array}{c}\text { Mean (SD) } \\
\text { Systolic blood } \\
\text { pressure at } \\
\text { baseline }\end{array}$ & $122.44(22.3)$ & 117.77 (17.44) & 4.23 & $\begin{array}{c}{[-14.30} \\
23.66]\end{array}$ & 0.606 \\
\hline \multicolumn{6}{|c|}{$\begin{array}{l}95 \% \text { CI and p-value reported from Independent sample t-test } \\
* * \text { Above } 100 \text { bpm is considered as Fast Heart Rate. Any measurements below } 100 \mathrm{bpm} \\
\text { is considered as normal heart rate. } \\
\text { SPSS version } 26 \text { site, was used to analyze and conduct statistical analysis of blood sugar } \\
\text { levels, blood pressure and heart beats by means of a t-test. Two t-tests were provided to } \\
\text { clearly demonstrate the correlation between energy drink consumption and its effects. }\end{array}$} \\
\hline
\end{tabular}

\section{Discussions}

Commercial advertising of energy drinks has been obviously focusing on the young generation, where it has become a custom in every house for the teenagers that Red Bull gives you wings [15].In fact, these advertisements do not reflect the truth of these drinks, that they cause adverse effects while increasing physical and mental activities [16].Consumers tend to drink these energy drinks during sport activities, driving to stay alert, exams and special occasions such as weddings and social gatherings. Over the past 10 years, energy drink industries have been increasing dramatically and spreading widely [17]. According to the study, the prevalence of energy drink consumption in Kuwait is $58.3 \%$, (61.2\% males, $56.0 \%$ females) in a population ranging between 10 to 30 years old. Furthermore, high school students were the most affected by advertisements as the prevalence was $78.3 \%$ for males and $77.6 \%$ for females, the highest between our age groups. While in Italy the consumption of energy drinks among high school students did not exceed 28\% [10]. According to this study, in Kuwait the most common reason for consuming energy drinks was enjoying its taste (45.4\%) and for increasing energy in general (30\%).

Several research and studies have shown that these drinks cause many hazards to human health as they lead to several side effects and in some cases lead to death; two cases of sudden deaths were reported in Kuwait $[1,18]$. Through field research and a surveillance system that were performed in this study, it was very clear that there was a lack of awareness and knowledge of health and nutritional status in the participants. A high number of consumers (12.6\%), especially females (84.4\%), reported not feeling any side effects; however, it was clear that they were unaware of the difference between side effects and regular fatigue, since loss of sleep had a high prevalence of $20.1 \%$. Other side effects related to fatigue were also high, such as headache at $24.5 \%$ and rapid heartbeat at $23.7 \%$. Furthermore, recent studies on consumption patterns in Europe have found that caffeine overdose can cause fatal outcomes [19].

The Food and Drug Administration (FDA) has included caffeine in the list of substances that are generally recognized as safe and has set the maximum concentration of caffeine in cola beverages at $32.4 \mathrm{mg}$ of caffeine per 6-oz bottle or $65 \mathrm{mg}$ of caffeine per $12 \mathrm{oz}$ (Food and Drug Administration 1998) [20]. Additionally, caffeine found in coffee and tea, when consumed in high doses may lead to abnormal stimuli that can cause insomnia, drowsiness, 
stomach irritations, headaches, agitation and chest pain. For instance, several components in both coffee and tea can lead to downregulation of tumor suppressor proteins and DNA repair enzymes found in the body [21]. Thereby, we have used only $150 \mathrm{ml}$ of Red Bull on our participants, to be within the safe concentration of caffeine (41 mg/serving). A slight elevation in blood glucose from $5.7 \mathrm{mmol} / \mathrm{L}$ to $7.3 \mathrm{mmol} / \mathrm{L}$ within 30 minutes, followed by a decrease to the baseline was observed. This increase, even though minute, is considered significant given the small amount of drink consumed. Nonetheless, we have noticed no dramatic change in blood glucose, heartbeat or blood pressure. All of these measurements were within the normal range during the 90 min of measurements.

\section{Conclusions}

On the basis of this survey, that aims to establish energy drink consumption patterns among different young Kuwaiti and identifying the prevalence of consumption. Kuwait has a high prevalence of energy drink consumption, $58.3 \%$ of 570 of children and young adults (10 to $30 \mathrm{y})$ consume one drink per month. Most common reason for this high prevalence is enjoying the energy drinks taste and increasing energy in general. No significant effects on blood were noticed for those who were monitored after consumption. Further research should perform blood tests when larger amounts of caffeine under medical supervision are consumed; this will help in revealing the side effects of these commonly consumed drinks. Moreover, in Arab countries and worldwide, warnings and risks of these beverages should be printed on packages $\backslash$ as part of the country's legislation.

\section{Competing Interest}

The author(s) declare that they have no competing interest.

\section{Reference}

1. B. Malinauskas, V. Aeby, R. Overton, T. C. Aeby, K. B. Heidal, Nutritional J, A survey of energy drinks consumption among college students, 6 (2007)

2. S. Badih, UAE consumes $12 \mathrm{~m}$ liters of energy drinks every year, Gulf News, http://gulfnews.com/business/features/uae-consumes-12m-litres-of-energy-drinksevery-year-1.597607, (2010)

3. Y. Kaminer, Child Adolesc Psychiatric Clin N Am, Problematic use of energy drinks by adolescents, (2010)

4. W. Ishak, C. Ugochukwu, K. Bagot, D. Khalili, C. Zaky, Innov Clin Neurosis, Psychological effects and impact on well-being and quality of life- - literature reviews, (2012)

5. M. Rath, J Am Acad Nurse Pract, Energy drinks: What is all the type? The dangers of energy drink consumption, (2012)

6. R. McCusker, B. Goldberger, C. Edward, J. Analytical Toxicology, Caffeine content of energy drinks, carbonated sodas, and other beverages, (2006)

7. K. Yifrah, J. Elsevier, Problematic use of energy drinks by adolescents, (2010)

8. A. Peacock, R. Bruno, F. H. Martin, Alcohol Clin Exp Res, The subjective physiological, psychological, and behavioral risk-taking consequences of alcohol and energy drink co-ingestion, Alcoholism: Clinical and Experimental Research, (2012) 
9. N. Pennington, M. Johnson, E. Delaney, M Blankenship, J. School Nursing, A new health hazard for adolescents, (2010)

10. S. Scuri, F. Petrelli, M. Tesauro, F. Carrozzo, L. Kracmarova, I. Grappasonni, J Prev Med Hyg, Energy drink consumption: a survey in high school students and associated psychological effects, (2018)

11. University of Miami Miller School of Medicine. Journal of Pediatrics. Available at http://pediatrics.aappublications.org/content/127/6/1182.full.html, (2011)

12. S. Seifert, L. Judith, R. Eugene, E. Steven, J Am Acad Nurse Pract, Health effects of energy drinks on children, adolescents, and young adults, (2011)

13. M. A. Almulla, KJS, Location-based Expert System for Diabetes Diagnnosis and medication recommendation, 48 (2021)

14. J. P. Higgins, T. D. Tuttle, C. L. Higgins, Myo Clin Proc. Energy beverages: content and safety, (2010)

15. F. Ragsdale, T. Gronli, N. Batool, N. Haight, A. Mehaffey, E. McMahon, Amino Acids, Effect of Red Bull energy drink on cardiovascular and renal function, (2010)

16. AX. Bigard, J. Elsevier, Risks of energy drinks in youths (2011)

17. G. Smith, Daily Mail, Three deaths linked to energy drinks, http://www.dailymail.co.uk/health/article-59862/Three-deaths-linked-energydrink.html, (2001)

18. G. Elliott, Sales of Energy Drinks Continue to Increase. Street Directory,http://www.streetdirectory.com/food_editorials/beverages/beverages/sales_o f_energy_drinks_continue_to_increase.html, (2008).

19. J. J. Breda, S. H. Whiting, R. Encarnacao, S. Norberg, R. Jones, M. Reinap, J. Jewell, Front Public Health, Energy drink consumption in Europe: A Review of the Risk, Adverse Health Effect, and Policy Options to Respond, (2014)

20. L. K. Roth, FDA, Caffeine in nonalcoholic carbonated beverages, 86 (1998)

21. Webmd.com. 2018. CAFFEINE: Overview, Uses, Side Effects, Precautions, Interactions, Dosing and Reviews. Available at:

https://www.webmd.com/vitamins/ai/ingredientmono-979/caffein 